\title{
LA BELLEZA DE SER SACERDOTE EN LA CULTURA ACTUAL
}

DOI: https://doi.org/10.52039/seminarios.v62i217.129

Ángel Cordovilla PÉREZ*

Las siguientes reflexiones podrían haber llevado sencillamente por título «ser sacerdote en la cultura actual». ¿Por qué anteponer a esta afirmación el sustantivo «belleza»? ¿Qué añade la expresión «la belleza de ser» al verbo «ser» sin más?

En primer lugar, la percepción concreta de lo que un sacerdote es desde el punto de vista ontológico y esencial. Resulta evidente que cuando queremos contemplar el sacerdocio en su belleza intrínseca y no sólo en su deber moral tenemos que tomar como base lo que lo define desde un punto de vista teológico y esencial; sin embargo, al hablar aquí de belleza tratamos de subrayar la existencia concreta del sacerdote en el marco de la cultura actual. Cuando en los últimos tiempos la teología ha propuesto el trascendental de la belleza para contemplar la figura de la revelación que es Cristo, ha querido ir más allá del racionalismo y moralismo ilustrado que desde sus condiciones apriorísticas quiso imponer la forma de aparición de esa figura. Si lo primero es la belleza como expresión de la verdad interna de una realidad, pero manifestada en su figura concreta e histórica y no ideal, entonces al contemplarla debemos dejar que ella se nos dé y se nos muestre en toda su dimensión y en total libertad, sin imponerle nuestros presupuestos $u$ horizontes culturales, con frecuencia demasiado estrechos.

Por eso, en segundo lugar, habría otra nota importante en el sustantivo belleza acompañando al verbo ser. Este término no podemos entenderlo desde un punto de vista puramente estético y mucho menos cosmético, al menos tal y como estos conceptos son entendidos hoy. Con el término belleza queremos subrayar la gracia de ser sacerdote, como un don previo a nuestra decisión personal; la alegría que supone ser llamado por el Señor a este ministerio, antes que las decisiones y opciones morales que conlleva. No porque haya que ocultar este «deber ser» o imperativo que nace del

* Profesor de Teología dogmática en la Universidad Pontificia de Comillas, Madrid. Conferencia pronunciada en el 8 de marzo de 2016 en Salamanca. 


\section{Ángel Cordovilla Pérez}

don recibido, sino porque hay que ponerlo en su justa relación. La tradición cristiana ha comprendido unidas la acción del Espíritu en la creación con la belleza de la obra creadora, como acción perfectiva que lleva adelante y consuma el don y la vocación original que Dios ha puesto en ella.

De aquí que la belleza de ser sacerdote, finalmente, se muestre ante todo en el contraste que resulta de la confluencia entre el don de Dios que es dado de una vez para siempre en el sacramento del orden y la fragilidad humana de la existencia concreta del sacerdote, que va siéndolo a lo largo de toda su vida. Su belleza no está en aparecer ante el mundo desde una santidad y perfección separada del resto de los mortales, sino en la docilidad al Espíritu de Dios que va conformando en la ambigüedad y paradoja de nuestra vida la imagen de Jesucristo. Por esta razón, cuando hablamos de la belleza de ser sacerdote aparece a la vez su gracia y su cruz; su gloria y su peso; su atractivo y su extrañeza, tanto para el sujeto que lo vive como para la sociedad y la cultura que lo rodea.

\section{LA BELLEZA DE SER UN DISCÍPULO}

A menudo se nos olvida que un sacerdote es ante todo una persona llamada por el Señor para ser su discípulo. Ser sacerdote no comienza por una decisión personal, sino por la llamada de Otro. En una sociedad donde la libertad personal y la autonomía se ha convertido en una realidad sagrada, ser cura comienza por la decisión y la libertad de otra persona. Esta realidad cuesta percibirla, porque al inicio parece que se trata de una decisión personal que nace de la libertad individual, pero una va aprendiendo que esto, sin ser falso, no es toda la verdad, ni siquiera la verdad primera ni la más radical. La historia de un sacerdote no comienza cuando él decide ser sacerdote, sino que siempre comienza en la llamada libérrima y gratuita de Dios. Él es quien decide en su amor y misericordia compartir con los hombres la misión de su Hijo, asociándolos a su tarea, a su misión y a su persona. Por este motivo, por mucho que un sacerdote avance en el camino de su vocación, siempre ha de ser consciente de que es un discípulo que sigue al Señor. El inicio de su ser y su vocación no está en él, sino en ser llamado por Dios. Y por esta razón, pertenece a la esencia y naturaleza de su vocación y de su vida mantenerse con fidelidad en el seguimiento de su Hijo. En 1957, el sacerdote Jorge Sans Vila hizo una encuesta entre diversos sacerdotes preguntándoles el motivo por el cuál se hicieron sacerdotes. La respuesta de uno de ellos, llamado Hans Urs von Balthasar, es sobrecogedora: «Tú has sido llamado, tú no servi- 
rás, hay quien se servirá de ti; tú no debes hacer proyectos, no eres más que una piedra pequeña de un mosaico preparado desde hace tiempo. Yo no debía más que abandonarlo todo y seguirle» (Por qué me hice sacerdote, Salamanca 1980). En realidad, resuenan las palabras de Jesús en el evangelio cuando dice a sus discípulos: «No sois vosotros los que me habéis elegido, soy yo quien os he elegido y os he destinado para que deis fruto» (Jn 15, 8). O aquellas del evangelio de Marcos, que subrayan con fuerza que cuando Jesús eligió a los Doce apóstoles Ilamó a los que él quiso (Mc 3,13-16). Un querer de Jesús que implica su libre voluntad y decisión soberana, a la vez que el amor que deposita en quien es elegido libre y gratuitamente.

Esta verdad previa fundamental vinculada al origen de la vocación sacerdotal, no se queda en el inicio, sino que es fundamento necesario para toda la vida apostólica. Un sacerdote siempre es un discípulo. Nunca está el discípulo por delante del maestro. Y desde esta lógica hay que entender el papel de la formación en el sacerdocio. Por supuesto que toda profesión necesita su capacitación para ejercerla. Y el oficio sacerdotal también requiere la formación necesaria. Pero esta formación es la expresión concreta de que un sacerdote siempre es un discípulo. Esta se vive con intensidad en el tiempo del seminario, donde el futuro sacerdote, a la vez que profundizar en la pureza de su intención y en la verdad de la vocación, va tomando conciencia de esa precedencia de Cristo sobre su vida y sobre su llamada. Ni siquiera la vocación le pertenece a él, sino a Cristo y a su Iglesia. Ese proceso de expropiación hacia Cristo y de objetivación de su vocación hacia la Iglesia es el hecho más importante y decisivo que ha de acontecer en el tiempo de formación para el sacerdocio (seminario).

Pero, como ha puesto de relieve la importante exhortación apostólica de Juan Pablo II Pastores dabo vobis, la formación sacerdotal es una exigencia permanente. Y la razón es la misma. No sólo para mantener la calidad de la capacitación para el desempeño de una función, sino porque el sacerdote siempre es un discípulo de Jesús, un seguidor de su Señor y Maestro. El déficit de la formación sacerdotal que vivimos en la actualidad es, en mi opinión, expresión de una crisis más profunda: los sacerdotes nos olvidamos fácilmente de nuestra condición de discípulos. Y esto en todas las dimensiones de nuestra vida: en la dimensión humana, intelectual, pastoral, espiritual y comunitaria. Es aquí donde se juega la posibilidad de la renovación de la vida y el ministerio de los presbíteros. Podemos cambiar las estructuras pastorales, puede cambiar la situación cultural y social, pero si no trabajamos en esta dimensión personal de la vocación 


\section{Ángel Cordovilla Pérez}

que nos haga ser conscientes de nuestro carácter esencial de discípulos de Jesús y seguidores de Cristo, al final serán cambios superficiales que no afectarán a la vida real de los presbíteros. Debemos reconocer que esto no es sencillo, pues la vida apostólica y misionera nos lleva a ser pastores y representantes visibles de la comunidad cristiana, a la que tenemos que acompañar y guiar; pero por otro lado nos vemos necesitados de ser acompañados y guiados por otros y por el Señor.

\section{LA BELLEZA DE SER UN APÓSTOL}

Sacerdotes, curas, presbíteros, apóstoles... Todos ellos son nombres que hemos utilizado en la historia de la Iglesia para referirnos a aquellos bautizados que en la Iglesia son elegidos para el ejercicio del ministerio ordenado. ¿Qué nombre utilizar? Todos son legítimos. Yo mismo los he ido utilizando aquí indistintamente. El Concilio Vaticano II también lo hace, aunque a la hora de exponer los principios fundamentales de su ser y su misión elige la expresión ministerio apostólico. ¿Por qué? ¿Qué consecuencias tiene esto para la comprensión del sacerdocio? Ante todo significa que el centro de referencia del sacerdocio es Cristo y los apóstoles. Superando una cierta comprensión reductora del decreto del Concilio de Trento sobre el sacerdocio, donde lo vinculaba exclusivamente al sacrificio de la Misa comprendido desde el sentido ritual del término sacerdocio, el decreto Prebyterorum ordinis del Concilio Vaticano II pone el centro de referencia en el envío del Hijo por parte del Padre. Dice así en el número 2:

El Señor Jesús, a quien el Padre santificó y envió al mundo (Jn 10, 36), hizo partícipe a todo su cuerpo místico de la unción del Espíritu con que él está ungido... El mismo Señor constituyó a algunos de ellos ministros que ostentando la potestad sagrada en la sociedad de los fieles, tuvieran el poder sagrado del orden, para ofrecer el sacrificio y perdonar pecados, y desempeñaran en nombre de Cristo la función sacerdotal a favor de los hombres... Así pues, enviados los apóstoles, como él había sido enviado por el Padre, Cristo hizo partícipes de su consagración y misión, por medio de los mismos apóstoles, a los sucesores de estos, los obispos, cuya función ministerial se ha confiado a los presbíteros, en grados subordinado, con el fin de que, constituidos en el orden del presbiterado, fueran cooperadores del orden episcopal, para el cumplimiento de la misión apostólica que Cristo les confirió.

El punto de partida para la comprensión del ministerio ordenado es la consagración y misión del Hijo enviado por el Padre. En esta misión está unido todo su cuerpo, que es la Iglesia, ungida y enviada por el mismo 
Espíritu de Cristo. Con una misión y consagración especial son enviados los apóstoles y sus sucesores, los obispos. Y desde este ministerio apostólico es comprendido el ministerio ordenado, los curas, los sacerdotes. Su función es obrar en nombre de Cristo Cabeza en tres órdenes o ministerios: el de la Palabra y anuncio del Evangelio, el de los sacramentos y la celebración de la Eucaristía, el de la guía y conducción del Pueblo de Dios en su camino hacia el Reino. Por esta razón, a mí el título que más me gusta para el sacerdote es el de apóstol de Jesucristo. Y la figura que para mí destaca en este sentido es Pablo de Tarso. Él, como cada uno de nosotros después, no hemos conocido personalmente al Jesús terreno, sino que ya seguimos al Señor resucitado. Para Pablo hay dos títulos que añade a su nombre en la presentación que él mismo hace en las cartas, poniendo de relieve cuál es su identidad más profunda. Los dos títulos son: esclavo de Cristo Jesús y llamado a ser apóstol (Rm 1, 1ss). Ambos significan una misma cosa: son expresión de dignidad; pero también de que es propiedad e instrumento en manos de Cristo. El título de apóstol sitúa el ser sacerdotal en dependencia absoluta del Hijo: tanto de su misión como de su persona.

Profundicemos brevemente en estos títulos desde la perspectiva paulina en la Carta a los Romanos, verdadero corazón del mensaje paulino. Con el título de esclavo se ve con claridad que a pesar de que este «evangelio» y esta carta son su síntesis personal, no se presenta en nombre propio, sino en el nombre de quien lo envía, en el nombre de su Señor. Esta absoluta dependencia se expresa de forma clara cuando utiliza dicho título. Aquí no está utilizando la expresión servidor (diakonos), sino esta expresión más escandalosa y radical que es la de «esclavo» (doulos), él, que se consideraba también un ciudadano libre. Ya en Filipenses se presenta como aquel que ha sido poseído y alcanzado enteramente por el Señor (Flp 3, 12). Por eso no se conforma con servir al Señor-aun siendo él, en el fondo, el señor y dueño de su propia vida-, sino que sirve al Señor y a su Evangelio siendo consciente de que ha pasado a ser propiedad del Señor y su instrumento. En una formulación muy fuerte podemos decir que se ha convertido en su propio cuerpo (cf. 1 Cor 15, 23; Rm 8, 9; 1 Cor 3, 23; 2 Cor $10,7)$. A pesar de que esta afirmación nos puede parecer extrema, esto es en realidad lo que hoy decimos cuando expresamos teológicamente que el apóstol y el sacerdote actúa in persona Christi. Una realidad que aparece de forma visible y lo realizamos ejemplarmente y de forma suprema en la eucaristía y en el sacramento de la reconciliación, aunque no de forma exclusiva. En estos sacramentos el sacerdote, apóstol y esclavo de Cristo 


\section{Ángel Cordovilla Pérez}

Jesús, dice "Tomad, esto es mi cuerpo»; «Yo te absuelvo en el nombre....». No decimos: "Tomad, este es el cuerpo de Cristo». Hasta ahora esta presidencia de la eucaristía la habíamos entendido como un poder sagrado y una dignidad personal. Y es verdad, pero este poder y esta dignidad están vinculados estrechamente al servicio como esclavo, tal como Pablo nos los enseña con su propia vida, siendo resplandor de la vida y ejemplo del Señor, que tomó la condición de esclavo (cf. Flp 2, 7).

Actuamos en nombre de Cristo, pero no somos Cristo. Aquí se produce de nuevo una tensión fundamental que muestra la belleza y grandeza oculta del sacerdote: entre la actuación en nombre y representación de Cristo como Cabeza de la Iglesia, y la frágil existencia personal, incluida la fragilidad del pecado. Cristo se hace presente en la fragilidad de la existencia del sacerdote. El que envía se hace presente en quien es enviado. Como dijo Benedicto XVI con especial belleza y profundidad en la homilía de la clausura del año sacerdotal (11 de junio de 2010): «El sacerdocio no es un simple 'oficio', sino un sacramento: Dios se vale de un hombre con sus limitaciones para estar, a través de él, presente entre los hombres y actuar en su favor. Esta audacia de Dios, que se abandona en las manos de seres humanos; que, aun conociendo nuestras debilidades, considera a los hombres capaces de actuar y presentarse en su lugar, esta audacia de Dios es realmente la mayor grandeza que se oculta en la palabra 'sacerdocio'».

Un momento decisivo para la dilucidación del sentido de esta actuación en nombre de Cristo respecto a la vida concreta del presbítero fue entre los siglos III y $\mathrm{V}$ con la controversia donatista en el norte de África. Es cierto que se trata de una situación límite y no puede ser esgrimida como forma normal de la dispensación de los misterios de Dios. Los sacramentos dispensados por el sacerdote que ha traicionado la fe católica, ¿son válidos? Los sacerdotes que llevan una vida pecadora, ¿tienen capacidad para santificar a través de sus palabras? Sí, porque ellos no representan a Cristo sustituyéndolo, sino que es Cristo quien por la fuerza del Espíritu se hace presente en su acción sacramental. Es Cristo quien anuncia el Evangelio, quien bautiza, quien preside la eucaristía. Todos, el sacerdote el primero, han de ser conscientes de esta distancia entre el ser y la misión. La vida del sacerdote entendida con el término clásico de ascética, está en ir acercando cada vez más estas dos dimensiones, pero siendo consciente siempre y con humildad de que esta distancia, tensión y paradoja son infranqueables.

El sacerdote no es [otro] Cristo, sino que es Cristo quien se hace presente a través de los gestos, palabras y acciones del sacerdote. Él no es 
Cristo, sino apóstol de Cristo y esclavo del Señor. Desgraciadamente por crímenes execrables e injustificables, en el momento actual de la historia de la Iglesia esta verdad fundamental hemos tenido que aprenderla de una forma excesivamente brusca. No podemos ni debemos idealizar la vida de los curas, ni exigirles la santidad de Jesucristo. La santidad es de la Iglesia y el resto de los miembros somos pecadores que intentamos no ser obstáculo a la mediación salvífica que Cristo obra por medio de cada uno de nosotros. El ser representación de Cristo en la actuación salvífica (no en todo lo que hacemos, aunque deberíamos estar llamados a ello) no puede llevar a una consideración angélica de los sacerdotes. La expresión clásica, muy utilizada, de que el sacerdote es un alter Christus, o la más moderna de ser pura trasparencia del Buen Pastor, siendo verdaderas y teniendo una intuición auténtica, pueden conducir a un grave error: que el sacerdote sustituye la presencia de Cristo, simplemente la hace presente de forma sacramental; y la mediación sacramental nunca es pura trasparencia; siempre se da en la ambigüedad y fragilidad de la existencia humana. No a pesar de ella, sino en ella, a través de ella.

Esta es la audacia de Dios y aquí está la belleza de ser sacerdote. Y así lo entendió Pablo de Tarso cuando en la Segunda Carta a los Corintios afirma desde su experiencia personal que la fuerza y gracia de Dios se realiza en la debilidad del apóstol. Una de las pruebas más duras de la vida sacerdotal es experimentar el fracaso de que la realidad que uno empieza a vivir en su ministerio (ya sea personal, comunitaria, eclesial o social) no coincide totalmente con los deseos que uno ha ido creando a lo largo de la formación para el sacerdocio en el seminario. Aprender a integrar esta situación, haciéndola momento de gracia, es una cuestión decisiva para la perduración en la vocación y el ministerio recibido. Creo que no solucionar esta cuestión es una de las causas de las secularizaciones de los sacerdotes en los primeros años de ministerio. El Evangelio, el Cuerpo de Cristo, el Reino de Dios, son realidades que nos superan infinitamente y respecto a las cuales nunca podremos estar a la altura de las circunstancias. Asumir con humildad esta pobreza y vivirla como un acicate para la santificación personal es algo constitutivo de la vida del apóstol, pues hace que no pueda apropiarse nunca de nada: ni del evangelio, ni de la comunidad eclesial a la que es enviado, ni de los frutos apostólicos que puedan darse a través de su acción pastoral, es decir, que sea más consciente de que es apóstol de Jesucristo y esclavo de su Señor. Es ahí, y no el éxito, donde puede decir realmente aquella otra expresión paulina de que «ya no soy yo, sino que es Cristo quien vive en mí» (Gal 2, 20). 


\section{Ángel Cordovilla Pérez}

\section{LA BELLEZA DE SER UN HERMANO}

En tercer lugar, el ministerio ordenado se da en la Iglesia y en una forma constitutivamente eclesial. La belleza de ser sacerdote se trasforma en la belleza de ser un hermano. Junto a la intransferible llamada personal, Jesús llamó a los discípulos como grupo. El ministerio ordenado tiene su forma plena de expresión y comprensión en el obispo, sucesor de los apóstoles. Y el obispo, a su vez, no puede entenderse de forma aislada, sino como miembro del colegio apostólico, unido a la cabeza de este cuerpo que es el sucesor de Pedro, el obispo de Roma. Los presbíteros son colaboradores de los obispos. No les deben a ellos el ministerio sacerdotal, sino que participan directamente del único sacerdocio de Cristo. Pero en el ejercicio de su misión han de realizarlo en comunión plena con él. Y además, la forma plena de comprensión del presbítero es en el presbiterio, lugar donde se expresa la fraternidad sacerdotal. La forma plena de ser ordenado presbítero, y por lo tanto también de su ejercicio y su forma de vida, es en plural, es decir, como presbíteros. Y no hace falta que un sacerdote pertenezca a una comunidad eclesial concreta o a una orden religiosa que tiene en el centro de su carisma y de sus votos la vida comunitaria. Aquí la comunidad es sacramental. Es decir, no nace de un voto o de una regla, sino de la naturaleza misma del sacramento del orden; está dada con el sacramento mismo. No es una cuestión opcional o carismática, sino constitutiva del ser sacerdotal. Y esto lo hace más exigente y a la vez lo más frágil.

Desde mi punto de vista, aquí se juega mucho de la misión de la Iglesia y de la salud personal del clero en el futuro. Pues la dimensión comunitaria de la vida y misión del ministerio ordenado está pidiendo una reforma de las estructuras pastorales de la Iglesia. Si antes hablaba de que la desproporción no asumida entre deseo y realidad puede provocar en muchos casos la secularización, una falta de vida eclesial y comunitaria lleva a otro tipo de problemas, como por ejemplo el de la funcionalización de la vocación, convirtiendo el ministerio en una profesión pública con horario determinado, dejando la vida privada para otros menesteres, y así, a la larga, creando de hecho una doble vida. Hace unos años, leyendo un libro del cardenal Lehamnn me sorprendió que una de sus preocupaciones respeto a la vida del clero fuera que estos no quisieran tener más en su casa un ama de llaves. Para un cura español esta afirmación es muy sorprendente, pues para su sueldo pagar este tipo de servicio es imposible. Pero la cuestión de fondo a la que apunta el cardenal es el problema de la privatización de la vida, el ais- 
lamiento y el individualismo. La vida aislada, con falta de participación en el presbiterio en comunión real con otros sacerdotes, tiene un grave peligro de provocar una secularización de hecho en la vida del presbítero, se formalice o no en una secularización real, o sea vivida a través de la funcionalización del ministerio o una doble vida.

Esta dimensión comunitaria de nuestra vida sacerdotal se vuelve más necesaria en nuestro contexto histórico y eclesial actual. La situación de diáspora y fragilidad que vive hoy la Iglesia, y dentro de ella especialmente el orden de los presbíteros, va a hacer de esta comprensión comunitaria de la vida y el ser sacerdotal una cuestión decisiva para la misión y evangelización de la Iglesia. Porque en un futuro cercano, desde los datos que tenemos en la actualidad, esta situación de diáspora personal y fragilidad institucional no se va a invertir, sino más bien a profundizar. ¿Podremos seguir manteniendo la forma de vida actual de tantos sacerdotes solos y aislados que tiene que atender comunidades pequeñísimas que no tienen capacidad ni para soportar una celebración digna de la eucaristía dominical? Los sacerdotes tendremos que asumir de verdad en nuestra forma de vida y actividades pastorales que la representación de Cristo Cabeza y Pastor de su Iglesia no es del sacerdote aislado que lo hace todo y sabe hacer de todo, sino la del obispo con su presbiterio.

Junto a esta dimensión comunitaria del ser sacerdotal respecto al obispo y otros sacerdotes, hay que tener en cuenta que el sacerdote es un hermano entre hermanos con otros miembros de la Iglesia. Que el presbítero sea apóstol de Cristo que actúa en representación suya como Cabeza de la Iglesia, no puede inducir a pensar que el sacerdote está fuera de la Iglesia. La alteridad que significa este actuar en nombre de Cristo ha de ser correspondida con la conciencia de ser y vivir en la comunión íntima de la Iglesia como uno más. No para disolver su ministerio y sacerdocio en el sacerdocio común o entenderlo desde una delegación de la comunidad cristiana hacia él para el ejercicio y desempeño de una función, sino para enraizar de hecho su ministerio en la comunión eclesial. Y nuevamente esta dimensión teológica hay que saber concretarla en una perspectiva histórica y concreta. Tanto en las estructuras pastorales poniendo de relieve que los seglares, participando directamente de la misión de Cristo, sacerdote, profeta y rey, son auténticos colaboradores de la única misión de la Iglesia, como en la vida diaria y en las relaciones personales, evitando de esta manera el clericalismo que tanto nos afecta y nos enferma a los sacerdotes. 


\section{Ángel Cordovilla Pérez}

\section{LA BELLEZA DE SER UN HOMBRE}

El sacerdote es un hombre. La belleza de ser sacerdote no puede darse separada de esta verdad fundamental, muchas veces olvidada. El sacerdote es un ser humano y nunca deja de serlo. Los actuales estudios sobre el perfil sociológico de los sacerdotes más jóvenes ponen de relieve que se está produciendo un «retorno a lo sagrado». La desacralización realizada de la figura del presbítero en los años posconciliares ha ido dando paso, poco a poco, a una nueva sacralización de su vida y su misión. Da la impresión que se está produciendo un típico movimiento pendular característico en las sociedades y en las instituciones. Son muchas las razones que se concitan en este hecho para que podamos resolverlas aquí. Tampoco es esta mi intención. Más bien quiero poner de relieve y en valor la doctrina conciliar en torno al ministerio apostólico presbiteral, donde la dimensión secular es esencial a su ser y a su espiritualidad. Una secularidad que no podemos entender como una mundanización, pues el carácter secular de la Iglesia, de todo cristiano y del sacerdote es vivido siempre desde una tensión interna que nunca puede desaparecer: del mundo, sin ser del mundo. El número 3 de Presbyterorum ordinis tiene en cuenta esta dimensión secular de la vida del presbítero poniendo de relieve lo paradójico de su existencia, desde donde, de nuevo, aparece también su belleza y dignidad: «No podrían ser ministros de Cristo si no fueran testigos y dispensadores de otra vida más que la terrena, pero tampoco podrían servir a los hombres si permanecieran extraños a su vida y sus condiciones». Para expresar esta tensión interna a la vida sacerdotal y a la vida cristiana cita el comienzo del capítulo 12 de la Carta a los Romanos, donde Pablo, a la vez que exhortar a hacer de nuestra propia vida una ofrenda agradable y espiritual a Dios, nos pide no conformarnos a este mundo, sino más bien transformarnos en el lugar donde se toman las decisiones de la vida, en la mente, viviendo plenamente nuestra condición humana y creatural (cf. Rm 12, 1-2).

Durante unos ejercicios espirituales en el Monasterio de Leyre en agosto del 2014, cayó en mis manos una obra sobre el sacerdocio con un título llamativo: El sacerdote inmaduro. Un itinerario espiritual (Stefano Guarinelli, Sígueme, Salamanca 2014). No quiero hacer una burda publicidad, pero el [autor del] libro me ayudó a entender muchas cosas de mi vida sacerdotal en su desarrollo concreto, y podríamos decir aquí que me ayudó a entender parte de su belleza y su drama. La tesis fundamental del libro es que la inmadurez propia de la vida humana, también de la vida del sacerdote, es algo que configura nuestro ser y forma parte de nuestra psicología. Cuando 
nos descubrimos con ella en el camino de la vida, no ha de asustarnos, sino que puede ser una rendija, una grieta, a través de la cual podemos entrar más intensamente en el misterio de la encarnación y así vivir nuestro ministerio en el tejido de la vida real y concreta de los hombres. Esta puede descubrirse en que no trabajamos con la intensidad suficiente guardándonos algo para nosotros mismos; en que nuestra intención en las acciones que realizamos no nace todavía de una voluntad absolutamente disponible a Dios (obediencia); que seguimos siendo esclavos de tantas cosas (libertad); que no amamos con la gratuidad y generosidad con la que nosotros hemos sido amados. La inmadurez, de suyo, no es mala, sino una ocasión para el crecimiento, pues cuando se vive o se quiere vivir desde la obediencia al Evangelio, siendo conscientes de nuestra limitación, puede ser un paso en el camino de ir llegando a la plena madurez en Cristo.

Cuando en virtud del sacramento del orden la teología afirma que representamos a Cristo, no somos conscientes de que esto se da en el orden sacramental y especialmente en el contexto litúrgico. Después, esta verdad ha de ir siendo auténtica en nuestra existencia humana, en las principales dimensiones donde se realiza: en las manos que trabajan, en la inteligencia desde donde pensamos, en nuestra voluntad desde la que en libertad obramos, en el corazón desde el que amamos. Y es aquí donde siempre nos vemos faltos e inmaduros. Asumir esta distancia, siendo conscientes de nuestra real humanidad, compartida con otros seres humanos, no nos saca de nuestro ser y de nuestra vida sacerdotal, sino que la enraíza en el mundo concreto y nos hace solidarios del camino de tantos hombres y mujeres de nuestro tiempo que, como nosotros, son llamados a consumar su vida en la única vocación humana. El trabajo con el que nos ganamos el sustento, la inteligencia que ponemos al servicio de la vida, la voluntad con la que obramos en libertad y el amor con el que amamos a nuestros semejantes forman parte de nuestro ser sacerdotal, y es ahí donde ha de mostrarse nuestra caridad pastoral y la pálida imagen y representación de Cristo, como Buen Pastor, que somos.

Sólo así aparecerá ante los hombres la belleza, en toda su gloria y su peso, de ser sacerdote en la cultura actual. 